\title{
Obstetric and neonatal outcomes to recombinant porcine somatotropin administered in the last third of pregnancy to primiparous sows
}

\author{
María E Trujillo-Ortega, Daniel Mota-Rojas ${ }^{1}$, \\ Rafael Hernández-González ${ }^{2}$, Elvia Yadira Velázquez-Armenta ${ }^{3}$, \\ Alejandro A Nava-Ocampo ${ }^{3}$, Ramiro Ramírez-Necoechea ${ }^{1}$, \\ Marcelino Becerril-Herrera ${ }^{4}$ and María Alonso-Spilsbury ${ }^{1}$ \\ Department of Animal Production: Swine, Facultad de Medicina Veterinaria y Zootecnia, Universidad Nacional Autónoma de México, México \\ ${ }^{1}$ Department of Animal Production and Agriculture, Research Area: Ecodesarrollo de la Producción Animal, School of Veterinary Medicine, \\ Universidad Autónoma Metropolitana-Xochimilco, México \\ ${ }^{2}$ Departamento de Investigación Experimental y Bioterio, Instituto Nacional de Ciencias Médicas y Nutrición Salvador Zubirán, México \\ ${ }^{3}$ Division of Clinical Pharmacology and Toxicology, The Hospital for Sick Children, 555 University Ave., Toronto, Ontario M5G 1X8, Canada \\ ${ }^{4}$ EIAH-Benemérita Universidad Autónoma de Puebla, San Juan Acateno, Teziutlan, Puebla, México \\ (Requests for offprints should be addressed to A A Nava-Ocampo; Email: navaocampo_aa@yahoo.com)
}

\begin{abstract}
This study aimed to investigate whether the administration of recombinant porcine somatotropin $(\mathrm{rpST})$ late in gestation is associated with increased rates of obstetric and neonatal complications in primiparous sows. From days 80 to 114 of gestational age, 20 primiparous sows were randomly assigned to receive an intramuscular injection of either saline or $6 \mathrm{mg} \mathrm{rpST} /$ day. Throughout pregnancy, sows were fed 2.5 to $3 \mathrm{~kg} /$ day of a cornsoybean diet (14 MJ ME/kg). Of 111 piglets born to control sows and 109 piglets born to treated sows, 8.1\% and $17 \cdot 4 \%$ piglets respectively died intrapartum $(P=0 \cdot 04)$. Glucose blood levels in sows and live-born piglets in the
\end{abstract}

rpST-treated group were significantly higher than in their corresponding controls. Birth weight of live-born piglets in the treated group was $1 \cdot 4 \pm 0 \cdot 1 \mathrm{~kg}$ versus $1 \cdot 3 \pm 0 \cdot 1 \mathrm{~kg}$ in the control group $(P<0 \cdot 0001)$. Birth weight of piglets born dead was also higher in the former than in the latter group $(P<0 \cdot 0001)$. No evidence of teratogenicity was observed in either of the groups. In conclusion, rpST administration in late pregnancy to primparous sows increased the rate of neonatal deaths and was associated with higher blood glucose levels in both sows and piglets. Journal of Endocrinology (2006) 189, 575-582

\section{Introduction}

Human fetuses with growth restriction have an increased risk of neonatal morbidity and mortality (Yanney \& Marlow 2004). Fetal growth is regulated by a complex mechanism in which somatotropin (ST) plays a key role throughout pregnancy (Gluckman \& Pinal 2003). Exogenous administration of ST seems to reverse the higher mortality rate and adverse neurological consequences associated with intrauterine growth retardation (Noeker 2005). In a study administering ST to sows at different gestational ages, it was observed that administration during early pregnancy induced the formation of significantly more muscle fibers in the semitendinosus muscle of fetuses; when given from days 50 to 64 of gestation there were no beneficial effects on fetal development, and when given from days 80 to 94 there were higher body weights and advanced stage of maturity at birth (Rehfeldt et al. 1993). The link between ST administered during pregnancy and an increased neonatal size in pigs was also confirmed by Gatford et al. (2004). Despite ST not crossing the placenta (Fholenhag et al. 1994), the metabolic effects directly induced by this hormone in the pregnant sow could alter fetal adaptation at birth and increase neonatal death. Therefore, this study aimed to evaluate whether $\mathrm{rpST}$ administration to primiparous sows in late gestation is associated with higher rates of obstetric and neonatal complications.

\section{Materials and Methods}

The study was approved by the Institutional Review Board at the School of Veterinary Medicine of the Universidad 
Autónoma Metropolitana-Xochimilco, and was performed in a commercial swine farm located in the State of Mexico, Mexico, in accordance with the FRAME's guidelines on papers involving the use of laboratory animals (http://www.frame.org.uk/reductioncommittee/ journalguidelines.htm) as well as with the guidelines on the ethical use of animals in applied ethological studies described elsewhere (Sherwin et al. 2003). It was assumed that procedures would add mild pain, suffering and distress to that expected during standard attention in the labor process. Cell phones, televisions or other sources of noise were not allowed in the production and delivery areas in order to decrease the sources of stress. Animals were treated humanely throughout the study.

\section{Animals}

Twenty crossbred Large White $\times$ Landrace gilts were bred with Landrace boars by artificial insemination at the time of their second estrus. The day of insemination was considered as the first day of gestation. During gestation, sows were housed in individual stalls with plasticized slatted-floors and water was available ad libitum. Sows received $2 \cdot 5$ to $3 \mathrm{~kg} /$ day of a corn-soybean diet balanced to meet current National Research Council requirements. The diet provided $14 \%$ crude protein, $0 \cdot 70 \%$ lysine, and $14 \mathrm{MJ} \mathrm{ME} / \mathrm{kg}$ of food, and remained similar throughout the pregnancy period.

Sows were housed in individual crates with concrete floors from the 4th day before the expected delivery date until the 21st postpartum day, a period that covered parturition and piglets' weaning. Delivery time was controlled by intramuscular injection of prostaglandins (Lutalyse; Pharmacia \& Upjohn, Mexico DF, Mexico) administered $36 \mathrm{~h}$ prior to the expected delivery date at 114 days of gestational age.

\section{Treatments}

Sows were randomly assigned to receive daily intramuscular injections in the neck region of either $1 \mathrm{ml}$ saline ( $n=10$ sows) or $6 \mathrm{mg} /$ day recombinant porcine ST (rpST) (Reporcin, Alpharma Animal Health Pty. Ltd, Victoria, Australia) in $1 \mathrm{ml}$ saline ( $n=10$ sows) from days 80 to 114 of gestation. The dose of $\mathrm{rpST}$ had previously been proved to increase fetal growth (Rehfeldt et al. 2001).

\section{Outcomes in the sows}

On days 80 and 114 of pregnancy, control and rpST-treated sows were weighed $(\mathrm{kg})$ and their dorsal subcutaneous fat $(\mathrm{mm})$ was measured by ultrasound (Renco Preg-Alert, Minneapolis, MN, USA). During parturition, the overall duration of parturition was registered as the time elapsed (min) from the rupture of amniotic membranes to the expulsion of the placenta. The time to deliver each piglet (time interval between piglets in min) was measured and averaged for each sow.

Within the first minute at the start of parturition, a blood sample was collected from any of the sow's ear veins for quantitation of glucose concentrations by a digital glucometer (Acuu-CheK; Active Roche Diagnostics $\mathrm{GmbH}$ ), blood lactate by enzymatic fotometry reflexion using a portable lactate analyzer (Accutrend Lactate, Sports Resource Group Inc, Hawthorne, NY, USA), and pH by a Ciba-Corning 278 Blood Gas System (Diamond Diagnostic Inc, Holliston, MA, USA); pH was corrected for body temperature. Body temperature was obtained instantaneously by a tympanic membrane thermometer (ThermoScan Braun GmbH, Kronberg, Germany). Finally, the litter size and placental weight were registered.

\section{Outcomes in the newborn piglets}

Each piglet was clinically examined in order to evaluate any objective evidence of external malformation. The following somatometric parameters were obtained: weight $(\mathrm{kg})$, crown-to-rump length $(\mathrm{cm})$, height $(\mathrm{cm})$, skull and hip width $(\mathrm{cm})$, thoracic circumference $(\mathrm{cm})$, and the hind limb circumference $(\mathrm{cm})$ measured in either of the hind limbs. Widths were obtained by a vernier caliper whereas the other somatometric parameters were obtained by standard bascules and metric tapes.

Piglets born dead were classified according to the criteria previously described in detail, as type I and type II piglets (Randall 1972, Mota-Rojas et al. 2002). Briefly, type I or antepartum stillbirths had a rather characteristic edematous and hemorrhagic appearance, sometimes a grayish-brown decoloration due to early mummification and, if the process was advanced then the fetuses were found dehydrated and losing hair. Type II or intrapartum stillbirths had the exact appearance of their normal littermates with the exception that they did not breathe. We also reported the number of live-born, meconium-stained piglets in each group.

Once the umbilical cord was ruptured, a blood sample was collected within the first minute after birth for biochemical evaluations. During sampling, no distinction was made between arterial and venous blood. Glucose, lactate, partial pressure of $\mathrm{CO}_{2}\left(\mathrm{pCO}_{2}\right)$ and $\mathrm{pH}$ blood levels were obtained as described above. Body temperature was obtained instantaneously by a tympanic membrane thermometer within the first minute of birth.

\section{Statistical analysis}

Data were summarized as means \pm S.D. or as median (and ranges). The sows' weight and back fat were compared between groups by a two-way analysis of variance (ANOVA) with repeated measures (with evaluation times and treatment as the between- and within-factors 
respectively). In this kind of analysis the total variation in the scores is broken down into 5 main sources of variation: (1) between-subjects factor (i.e. independent variable), (2) between-subjects error, (3) within-subjects factor (i.e. repeated measures), (4) within-subjects error, and (5) interaction of between- and within-subjects factors (Cramer 1998). The $F$ ratio for determining whether there is a significant effect for between-subjects factor is the between-subjects mean square divided by the between-subjects error mean square. The $F$ ratio for finding out whether the within-subjects factor is significant is the within-subjects factor mean square divided by the within-subjects error mean square, while the $F$ ratio for seeing whether the interaction effect is significant is the interaction mean square divided by the withinsubjects error mean square.

A Student's $t$-test for unpaired samples was used to compare the following variables between the two study groups in sows: duration of parturition, time interval between birth of piglets, placental weight, tympanic membrane temperature, glucose blood levels, and lactate blood levels, and in piglets: birth weight, crown-rump length, height, skull width, hip width, and thoracic and hind-limb circumference.

The litter size, $\mathrm{pH}$ blood levels in the parturient sows, and body temperature, glucose, $\mathrm{pH}$, lactate and $\mathrm{pCO}_{2}$ blood levels in the newborn piglets were compared between the two study groups by the Mann-Whitney $U$ test, a method defined by:

$$
U=n_{1} n_{2}+\frac{n_{2}\left(n_{2}+1\right)}{2}-\sum_{i=n_{1}+1}^{n_{2}} R_{i}
$$

where samples of size $\mathrm{n}_{1}$ and $\mathrm{n}_{2}$ are pooled and $\mathrm{R}_{i}$ are the ranks. The test can be resolved as the number of times observations in one sample precede observations in the other sample in the ranking. The alternative hypothesis was that values in one group tended to be distributed differently compared with the values in the other group.

As categorical variables, the number of intrapartum deaths ( $\%$ of all piglets) and meconium-stained piglets ( $\%$ of live born piglets) were compared between groups by $2 \times 2 \chi^{2}$ test, defined by:

$$
\chi^{2}=\sum_{i=1}^{r} \sum_{j=1}^{c} \frac{\left(O_{i j}-E_{i j}\right)^{2}}{E_{i j}}
$$

where for 2 rows $(r)$ and 2 columns $(c)$ of $n$ observations (4 cells in total), $\mathrm{O}$ is an observed frequency and $\mathrm{E}$ is an estimated expected frequency. The expected frequency for any cell is estimated as the row total times the column total divided by the grand total.

In order to evaluate whether the variations in the birth weight increased with piglet number in the two study groups, a two-way ANOVA for repeated measures (with piglet number and treatment as the between- and within-factors respectively) was performed as described above. In addition, a survival plot with comparison between groups of probability of survival was performed by the Cox-Mantel test as follows. The observations $X_{i a}$ for $K=2$ were considered as a series of contests between the two samples:

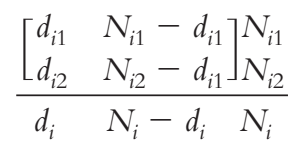

where the rows corresponded to the two samples $(a=1$, 2 ), the first column had the numbers of animals in each sample who were observed at time $t_{i}$, and the row sums were the number of animals in each sample who were 'at risk' at time $t_{i}$, and the second column had the number of animals who were ' at risk' at time $t_{i}$ but did not die. The Cox-Mantel type of statistic was based on the score:

$$
=\sum_{i=1}^{r} w_{i}\left(d_{i 1}-\frac{d_{i} N_{i 1}}{N_{i}}\right)
$$

where the observed deaths in the $K$ samples occurred at $\mathrm{r}$ distinct times $0=\mathrm{t}_{0} \leq \mathrm{t}_{1}<\mathrm{t}_{2} \ldots<\mathrm{t}_{\mathrm{r}}$, $d_{i}$ was the total number of observed deaths at time $t_{i}$ in the two samples, $N_{i}$ was the size of the total risk set at time $t_{i}$, and $w_{i}$ was an arbitrary weight equalling 1 . The null hypothesis was that the risk of death/event was the same in the two groups.

The investigators who did the evaluation and collected the study outcomes were not aware of the treatments and did not participate in the selection of animals or in the data analysis. The investigator who did the analyses was not aware of the treatments. A two-tailed $P<0.05$ was considered as significant in every test.

\section{Results}

\section{Outcomes in the sows}

The body weight at the start of administration of rpST was similar in the two groups (Table 1). On day 114 of gestation, there was an increment of approximately $10 \mathrm{~kg}$ in the rpST group and $20 \mathrm{~kg}$ in the control group. Statistical differences were observed between the two gestational days $(P<0 \cdot 0001)$ but not between treatments $(P>0 \cdot 05)$. The back fat in the two groups was similar at the start of the study (Table 1). At 114 days of gestation, dorsal fat loss decreased in the rpST-treated group whereas in the control group it remained unchanged; statistical differences were observed between the two gestational days $(P<0 \cdot 0001)$ but not between treatments $(P>0 \cdot 10)$.

The litter size was $11(10-13)$ piglets per sow in the rpST-treated group and 11 (9-13) piglets per sow in the control group $(P=0 \cdot 6)$. From piglet number 1 to 10,10 piglets were born per group. At piglet number 11 and $\geq 12,6$ and 3 piglets respectively were born in the 
Table 1 Comparison of clinical and laboratory evaluations between rpST-treated (6 mg/day from days 80 to 114 of gestation) and control groups

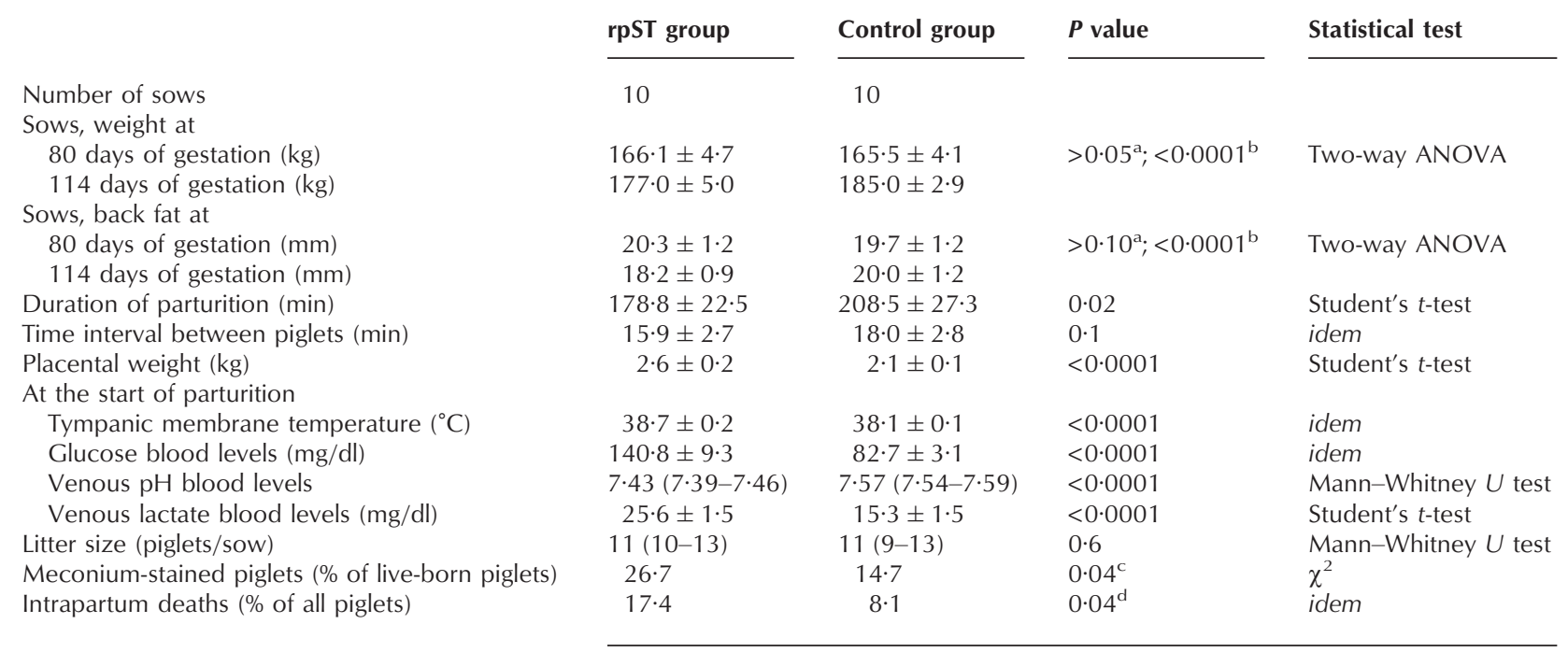

Data are means \pm S.D. or median (ranges). Placentas=10 per group. The total number of piglets born in the rpST and control groups was 109 and 111 respectively.

${ }^{\mathrm{a}}$ Between treatments and between evaluation times; ${ }^{\mathrm{c}} \chi^{2}=4 \cdot 2$; ${ }^{\mathrm{d}} \chi^{2}=4 \cdot 3$.

rpST-treated group, while 7 and 4 piglets respectively were born in the control group. In addition, placental weights were on average approximately $20 \%$ heavier in the treated group. Of relevance, duration of parturition was approximately $30 \mathrm{~min}$ shorter in the rpST-treated group (Table 1). Furthermore, the sows in the rpSTtreated group showed higher glucose blood levels, lower venous $\mathrm{pH}$ blood levels and higher venous lactate blood levels than the control group $(P<0 \cdot 005)$.

\section{Outcomes in the newborn piglets}

In total, 111 piglets were born to controls and 109 piglets to treated sows. Of these, $9(8 \cdot 1 \%)$ and $19(17 \cdot 4 \%)$ piglets respectively were classified as intrapartum deaths $\left(\chi^{2}=4 \cdot 3\right.$; $P=0 \cdot 04$ ) (Table 2). In the control group, the survival analysis showed that, starting at piglet number 7 , as the piglet number increased, the survival probability decreased (Fig. 1). However, in the rpST-treated group, the curve

Table 2 Comparison between the somatometric parameters observed in piglets born to rpST-treated sows and int hose born in the control group

\begin{tabular}{|c|c|c|c|}
\hline & rpST group & Control group & $P$ value \\
\hline Live-born piglets & $n=90$ & $n=102$ & \\
\hline Birth weight (kg) & $1 \cdot 4 \pm 0 \cdot 1$ & $1 \cdot 3 \pm 0 \cdot 1$ & $<0 \cdot 0001$ \\
\hline Crown-rump length $(\mathrm{cm})$ & $22 \cdot 2 \pm 1 \cdot 4$ & $21 \cdot 0 \pm 1 \cdot 7$ & $<0 \cdot 0001$ \\
\hline Height (cm) & $21 \cdot 3 \pm 0 \cdot 8$ & $20 \cdot 6 \pm 1 \cdot 5$ & $<0 \cdot 0001$ \\
\hline Skull width (cm) & $5 \cdot 6 \pm 0 \cdot 2$ & $5 \cdot 4 \pm 0 \cdot 3$ & $<0 \cdot 0001$ \\
\hline Hip width $(\mathrm{cm})$ & $5 \cdot 7 \pm 0 \cdot 3$ & $5 \cdot 5 \pm 0 \cdot 4$ & $0 \cdot 002$ \\
\hline Thoracic circumference $(\mathrm{cm})$ & $25 \cdot 6 \pm 1 \cdot 0$ & $24 \cdot 6 \pm 1 \cdot 4$ & $<0 \cdot 0001$ \\
\hline Hind-limb circumference $(\mathrm{cm})$ & $12 \cdot 9 \pm 0 \cdot 9$ & $12 \cdot 2 \pm 1 \cdot 5$ & $0 \cdot 0006$ \\
\hline Stillborns & $n=19$ & $n=9$ & \\
\hline Birth weight $(\mathrm{kg})$ & $1 \cdot 5 \pm 0 \cdot 1$ & $1 \cdot 1 \pm 0 \cdot 1$ & $<0 \cdot 0001$ \\
\hline Crown-rump length $(\mathrm{cm})$ & $23 \cdot 2 \pm 1 \cdot 4$ & $19 \cdot 7 \pm 1 \cdot 2$ & $<0.0001$ \\
\hline Skull width $(\mathrm{cm})$ & $5 \cdot 8 \pm 0 \cdot 2$ & $5 \cdot 1 \pm 0 \cdot 2$ & $<0.0001$ \\
\hline Hip width $(\mathrm{cm})$ & $5 \cdot 9 \pm 0 \cdot 4$ & $5 \cdot 1 \pm 0 \cdot 3$ & $<0 \cdot 0001$ \\
\hline Thoracic circumference $(\mathrm{cm})$ & $26 \cdot 5 \pm 1 \cdot 1$ & $23 \cdot 2 \pm 1 \cdot 2$ & $<0.0001$ \\
\hline Hind-limb circumference $(\mathrm{cm})$ & $13 \cdot 3 \pm 0 \cdot 8$ & $10 \cdot 8 \pm 0 \cdot 9$ & $<0 \cdot 0001$ \\
\hline
\end{tabular}

Data are means \pm S.D. All the parameters were compared between groups by an unpaired Student's t-test. 


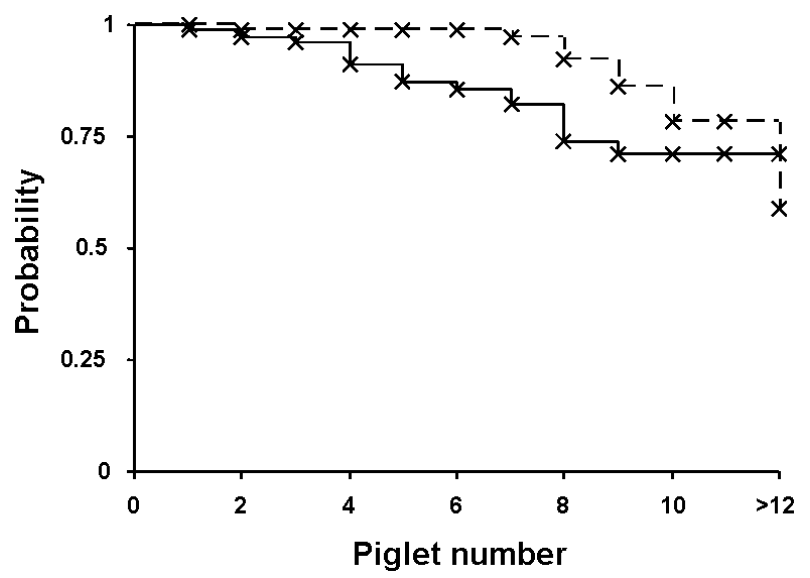

Figure 1 Comparison of survival of piglets born in the rpST-treated group (continuous line) and in the control group (dashed line). The probability of survival according to the piglet number was different between the groups $(P=0 \cdot 04)$.
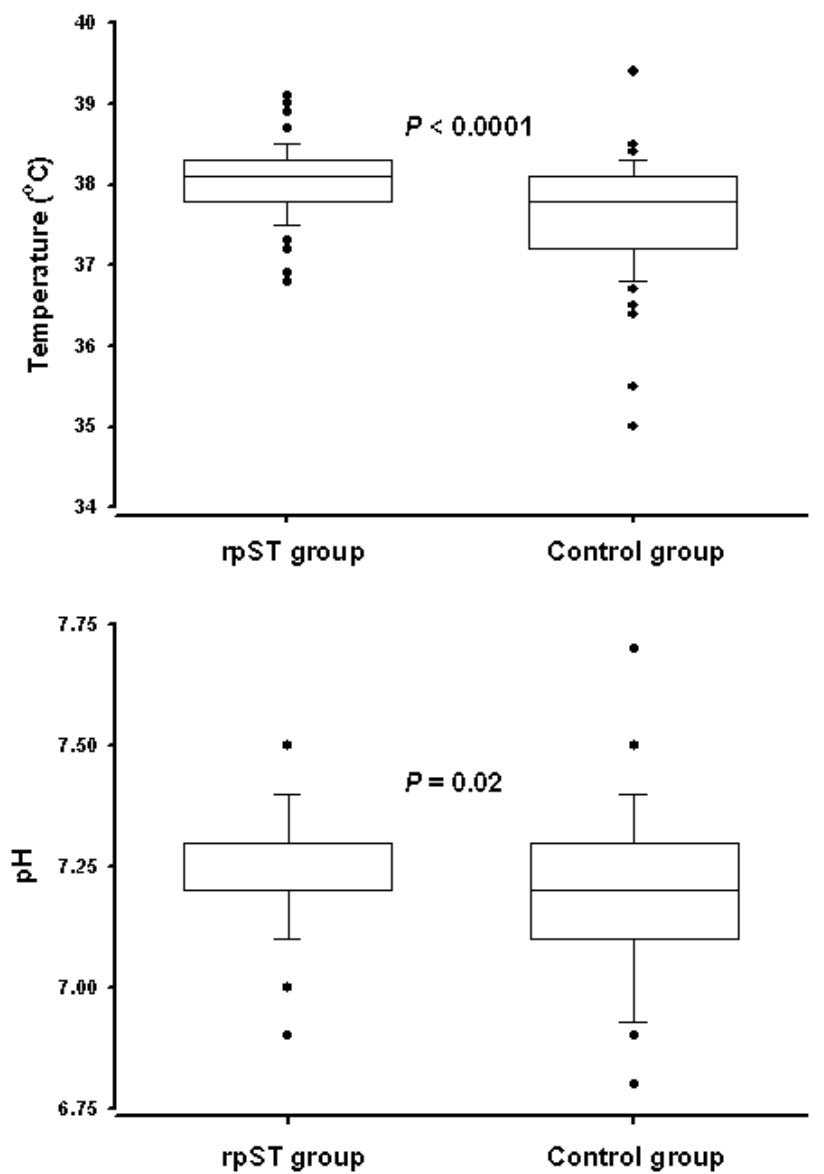

was shifted to the left and survival probability decreased at piglet number 1 . The survival analysis was different between the groups $(P=0 \cdot 04)$.

The group of piglets exposed in utero to the effects of maternal treatment with $\mathrm{rpST}$ showed a tympanic membrane temperature significantly higher than in the control group (Fig. 2). Glucose blood levels were approximately $5 \mathrm{mg} / \mathrm{dl}$ higher than controls. However, lactate and $\mathrm{pCO}_{2}$ levels were significanlty higher in piglets born in the control group than in piglets born in the rpST-treated group.

Live-born piglets in the rpST-treated group were approximately $1 \cdot 1$ times heavier than controls (Table 2), whereas the stillborn piglets were 1.4 times heavier in the former group than in the latter. In both cases, the difference was statistically significant $(P<0 \cdot 001)$. The birth weight from all the piglets born in the control group decreased with piglet number whereas in the rpST-treated group birth weight remained constant (Fig. 3). The two-way ANOVA for repeated measures was
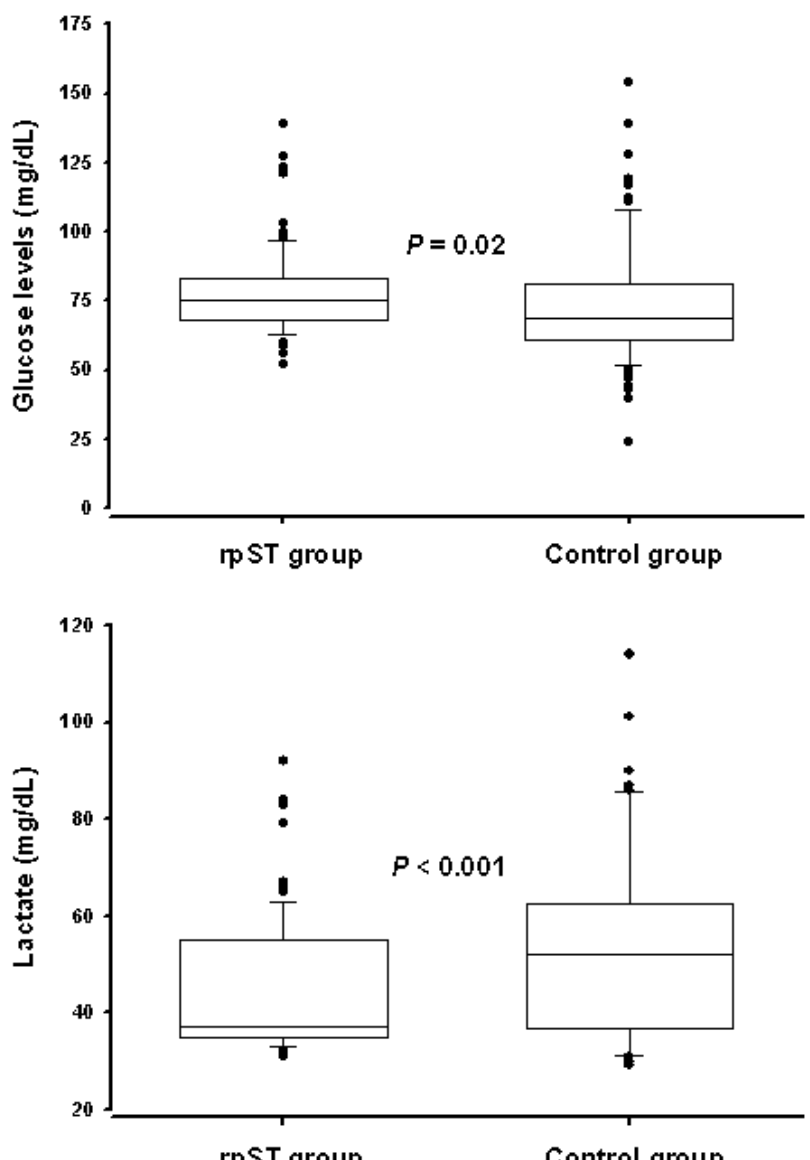

Figure 2 Comparison of tympanic membrane temperature and glucose, $\mathrm{pH}$ and lactate blood levels between live-born piglets in the rpST-treated group and the control group. The four parameters were statistically different (Mann-Whitney $U$ test). The lower boundary of the box indicates the 25th percentile, a line within the box marks the median, the upper boundary of the box farthest from zero indicates the 75th percentile, and the whiskers above and below the box indicate the 90th and 10th percentiles. For the $\mathrm{pH}$ levels of the rpST-treated group, the median was identical to the 25th percentile and therefore cannot be appreciated. 


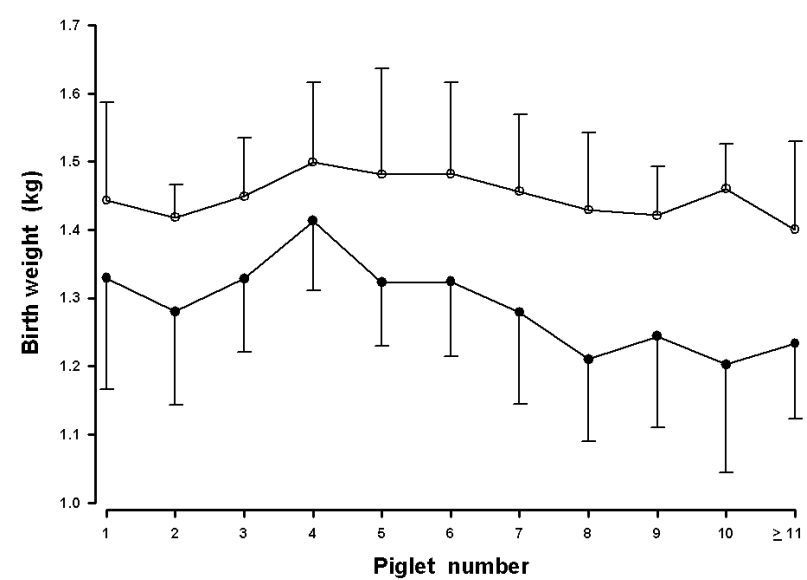

Figure 3 Birth weights in the rpST-treated group $(\bigcirc)$ were constant across the piglet number at parturition whereas in the control group $(-)$ they decreased $(P<0.0001$ for changes according to piglet number and $P<0 \cdot 01$ between treatment groups; two-way ANOVA for repeated measures). Data are means \pm S.D.

significant for changes according to both the piglet number and the treatment group $(P<0 \cdot 0001$ and $P<0 \cdot 01$ respectively). The other somatometric parameters collected from the live-born and the intrapartum death piglets were also significantly higher in the rpST-treated group (Table 2), further evidencing that piglets born to rpST-treated sows were significantly larger than controls. None of control or treated sows died during the study period or parturition, and none of the piglets was born with external evidence of birth defects.

\section{Discussion}

Our study confirmed that $\mathrm{rpST}$ administered in late pregancy favors fetal growth in pigs. The increased neonatal size observed in the present study was consistent with that reported elsewhere in the literature (Rehfeldt et al. 1993, Gatford et al. 2004). This effect may have relevance to the prospect of using ST during pregnancy to treat intra-uterine growth retardation in humans, especially in the light of accumulating evidence of the adverse impact of low birth weight in adult life. The 'early' origins of adult disease hypothesis (the Barker theory and the Brenner hypothesis) states that environmental factors, particularly nutrition, act in early life to program risk factors for chronic noncommunicable diseases in adult life, particularly systemic arterial hypertension, cardiovascular disease, diabetes, the metabolic syndrome and chronic renal insufficiency (Barker 2003, McMillern \& Robinson 2005, Reyes \& Manalich 2005). It is also clear from experimental studies that a range of molecular, cellular, metabolic, neuroendocrine, and physiological adaptations to changes in the early nutritional environment result in a permanent alteration of the developmental pattern of cellular proliferation and differentiation in key tissue and organ systems that may result in adverse health consequences in adult life (McMillern \& Robinson 2005).

Fetal growth seems to be affected not only by the amount of protein included in the maternal diet but also by the balance of macronutrients (Moore \& Davies 2005); fetal growth rate is sensitive to the supply of nutrients from maternal to fetal blood. This supply varies with the availability of circulating nutrients in the mother and the efficiency of their transfer across the placenta into the fetal circulation. Conditions that reduce the availability of substrates or those which reduce nutrient delivery across the placenta can retard fetal growth (Gluckman \& Harding 1997, Pardi et al. 2002), and severe maternal undernutrition reduces birth weight in humans (Stein et al. 1995, Godfrey et al. 1996). Conversely, maternal hyperglycemia increases placental glucose transfer and birth weight in humans and rodents (Herrera et al. 1985, Hauguel et al. 1986). In this study, significantly higher glucose blood levels were observed in rpST-treated sows than in controls and larger piglets were born in the former group, providing further support for the role of maternal hyperglycemia in fetal growth in mammals.

Somatotropin is an important modulator of insulin sensitivity, and both hormones are important regulators of cellular and whole body metabolism as well as somatic growth and body composition. The relationship between these two hormones was recently thoroughly reviewed by Dominici et al. (2005); ST counteracts the action of insulin on glucose homeostasis in both humans and animals, and a significant impairment of glucose metabolism may be observed after exogenous administration of ST in physiological or pharmacological doses in humans. In addition, both ST and insulin-like growth factor (IGF) have been linked to diabetic retinopathy (Frystyk 2005). In the present study, glucose blood levels in rpST-treated sows were 1.7 times higher than in controls at the start of parturition. Although they reached a statistical difference, glucose blood levels in the piglets born to treated sows were only 1.1 higher than the levels observed in the piglets born to control animals. The differences in the evident hyperglycemic effects observed in sows treated with rpST in late pregnancy and the modest rise in glucose blood levels in piglets can be explained by direct hormonal effects in the former and by a negligible effect in the latter due to the lack of placental passage of ST (Fholenhag et al. 1994). We failed to evaluate whether the hyperglycemia observed in sows treated with rpST from 80 to 114 days of gestation was promptly reversed. However, the higher glucose blood levels observed in their offspring was clinically insignificant and further studies are needed to clarify all the potential benefits and disadvantages that exogenous administration of $\mathrm{rpST}$ during pregnancy may provide as a therapeutic alternative for intrauterine growth retardation both in humans and animals. 
Fetal availability of nutrients is, however, regulated by a more complex hormone regulation than the interaction between ST and insulin. Maternal ST and IGF seem to be key determinants of fetal growth and birth weight (Chellakooty et al. 2004). In addition, the placenta produces a variant of ST that progressively replaces pituitary ST in the maternal circulation from midgestation (Frankenne et al. 1988), and has been correlated to birth weight in humans (Evain-Brion et al. 1994, McIntyre et al. 2000). In addition, fetal growth induced by maternal treatment with ST during early to mid-gestation may not necessarily be maintained to term (Gatford et al. 2004), whereas treatment during the late or greater part of gestation has been related to increased piglet size at birth, as occurred in the present study.

In our study, despite the fact that the diet was not adjusted according to the sows' gestational age, it provided 35 to $42 \mathrm{MJ} \mathrm{ME/day,} \mathrm{and} \mathrm{weight} \mathrm{gain} \mathrm{was} \mathrm{observed} \mathrm{in}$ both the control and the rpST-treated groups. However, weight gain was associated with back fat loss in the latter group. These changes were previously reported in other studies and may be explained by the repartitioning effect of rpST (energy from fat to muscle) observed in growingfinishing pigs and in ST-treated sows (Cromwell et al. 1992, Rehfeldt et al. 2001).

Human fetuses with growth restriction have an increased risk of neonatal mortality (Yanney \& Marlow 2004). This relationship was evident in the control group where the intrapartum death piglets had, on average, birth weights $15 \%$ lower than the live-born piglets. However, intrapartum death piglets in the rpST-treated group were, on average, $100 \mathrm{~g}$ (approximately 7\%) heavier than liveborn piglets in the same group. It may be hypothesized that such differences in birth weight were large enough to present difficult parturition in this group of sows.

During fetal hypoxia, blood redistribution may increase intestinal peristaltic relaxation of the anal sphincter leading to defecation of meconium into the amniotic fluid (Davis et al. 1985). In our study, more meconium-stained piglets were born in the rpST-treated group, which may reflect the difficulties in delivering them. However, piglets born in the control group were more susceptible to metabolic acidosis, judged by their lower $\mathrm{pH}$, and higher lactate and $\mathrm{pCO}_{2}$ blood levels at birth than those reported in the piglets born to treated sows. These contrasting results may support the view that $\mathrm{rpST}$ produces a combination of indirect effects in the piglets with a certain degree of relevance at birth that deserve to be explored in future studies.

Higher mortality rates have been reported with a larger number of piglets and at more advanced stages of parturition (Mota-Rojas et al. 2002, Borges et al. 2005). In the present study, the litter size did not differ between groups. Furthermore, although in the control group the number of intrapartum deaths increased with the piglet number, in the rpST-treated group the intrapartum deaths were mostly observed in the animals born in the first half of the litter. The contribution of weight at birth cannot explain this variability. In the control group, birth weight was lower in the last born piglets whereas the birth weight of piglets in the rpST-treated group did not vary throughout the progeny order. Therefore, the contribution of other mechanisms to the rate of intrapartum deaths in response to metabolic alterations induced in sows by rpST administration, cannot be ignored.

Previous studies evaluating rpST administration during pregnancy have observed a certain number of deaths in sows before and during parturition and lactation (Smith et al. 1991, Cromwell et al. 1992). The mortality seems to be dose-related, with death rates of 0, 6, 26 and 100\% in sows injected with $0,4,8$ and $16 \mathrm{mg}$ rpST respectively (Smith et al. 1991). We did not observe any case of maternal death in control or treated sows with $6 \mathrm{mg}$ rpST. However, sows treated with $\mathrm{rpST}$ had more metabolic acidosis compared with control sows, but the opposite relationship was observed in their offspring. These contrasting results suggest that whereas the sows were exposed to all the effects secondary to exogenous ST administration, different processes would be responsible for the changes observed at birth in the neonatal piglets.

In summary, $6 \mathrm{mg} \mathrm{rpST/day} \mathrm{administered} \mathrm{to} \mathrm{pregnant}$ sows from days 80 to 114 of gestation resulted in higher blood glucose levels in the sows and their offspring and in an increased rate of intrapartum deaths. In both study groups, piglets were born without external evidence of malformations. Considering the lack of transplacental rpST passage, whether the higher mortality rate observed in the offspring of rpST-treated sows was secondary to difficulties during parturition due to the increased piglets' size or to alterations in the metabolism of piglets secondary to maternal exposure to $\mathrm{rpST}$, remains to be elucidated in future studies.

\section{Acknowledgements}

The study was supported by a grant from the Programa de Mejoramiento del Profesorado (PROMEP) no. UAMPTC-028 to the Academic Staff of Etología, Production Porcina y Fauna Silvestre. M E T-O, D M-R and M A-S were supported, as members, by the Sistema Nacional de Investigadores. E Y V-A and A A N-O were recipients of the award 'Dr Rafael Ramos Galván' from the Sociedad Mexicana de Padiatria, A. C. (29 April 2006, México DF). The authors declare that there is no conflict of interest that would prejudice the impartiality of this scientific work.

\section{References}

Barker DJ 2003 The developmental origins of adult disease. European Journal of Epidemiology 18 733-736.

Borges VF, Bernardi ML, Bortolozzo FP \& Wentz I 2005 Risk factors for stillbirth and foetal mummification in four Brazilian swine herds. Preventive Veterinary Medicine 70 165-176. 
Chellakooty M, Vangsgaard K, Larsen T, Scheike T, Falck-Larsen J, Legarth J, Andersson AM, Main KM, Skakkebaek NE \& Juul A 2004 A longitudinal study of intrauterine growth and the placental growth hormone $(\mathrm{GH})$-insulin-like growth factor I axis in maternal circulation: association between placental GH and fetal growth. Journal of Clinical Endocrinology and Metabolism 89 384-391.

Cramer D 1998 Fundamental Statistics for Social Research: Step by Step Calculations and Computer Techniques using SPSS for Windows, pp 247-280. London, UK: Routledge.

Cromwell GL, Stahly TS, Edgerton LA, Monegue HJ, Burnell TW, Schenck BC \& Schricker BR 1992 Recombinant porcine somatotropin for sows during late gestation and throughout lactation. Journal of Animal Science 70 1404-1416.

Davis RO, Philips JB 3rd, Harris BA Jr, Wilson ER \& Huddleston JF 1985 Fatal meconium aspiration syndrome occurring despite airway management considered appropriate. American Journal of Obstetrics and Gynecology 151 731-736.

Dominici FP, Argentino DP, Munoz MC, Miquet JG, Sotelo AI \& Turyn D 2005 Influence of the crosstalk between growth hormone and insulin signalling on the modulation of insulin sensitivity. Growth Hormone and IGF Research 15 324-336.

Evain-Brion D, Alsat E, Igout A, Frankenne F \& Hennen G 1994 Placental growth hormone variant: assay and clinical aspects. Acta Paediatrica Supplement 399 49-52.

Fholenhag KI, Sandstrom IM, Malmlof K, Skottner AI \& Nyberg FJ 1994 Human growth hormone does not cross the placenta of pregnant rat. Growth Regulation 4 181-187.

Frankenne F, Closset J, Gomez F, Scippo ML, Smal J \& Hennen G 1988 The physiology of growth hormones (GHs) in pregnant women and partial characterization of the placental GH variant. Journal of Clinical Endocrinology and Metabolism 66 1171-1180.

Frystyk J 2005 The growth hormone hypothesis - 2005 revision. Hormone and Metabolic Research 37 (Suppl 1) 44-48.

Gatford KL, Boyce JM, Blackmore K, Smits RJ, Campbell RG \& Owens PC 2004 Long-term, but not short-term, treatment with somatotropin during pregnancy in underfed pigs increases the body size of progeny at birth. Journal of Animal Science 82 93-101.

Gluckman PD \& Harding JE 1997 The physiology and pathophysiology of intrauterine growth retardation. Hormone Research 48 11-16.

Gluckman PD \& Pinal CS 2003 Regulation of fetal growth by the somatotrophic axis. Journal of Nutrition 133 (Suppl 2) 1741s-1746s.

Godfrey K, Robinson S, Barker DJ, Osmond C \& Cox V 1996 Maternal nutrition in early and late pregnancy in relation to placental and fetal growth. British Medical Journal 312 410-414.

Hauguel S, Desmaizieres V \& Challier JC 1986 Glucose uptake, utilization, and transfer by the human placenta as functions of maternal glucose concentration. Pediatric Research 20 269-273.

Herrera E, Palacin M, Martin A \& Lasuncion MA 1985 Relationship between maternal and fetal fuels and placental glucose transfer in rats with maternal diabetes of varying severity. Diabetes 34 (Suppl 2) 42-46.
McIntyre HD, Serek R, Crane DI, Veveris-Lowe T, Parry A, Johnson S, Leung KC, Ho KK, Bougoussa M, Hennen G et al. 2000 Placental growth hormone (GH), GH-binding protein, and insulin-like growth factor axis in normal, growth-retarded, and diabetic pregnancies: correlations with fetal growth. Journal of Clinical Endocrinology and Metabolism 85 1143-1150.

McMillern IC \& Robinson JS 2005 Developmental origins of the metabolic syndrome: prediction, plasticity, and programming. Physiological Reviews 85 571-633.

Moore VM \& Davies MJ 2005 Diet during pregnancy, neonatal outcomes and later health. Reproduction, Fertility and Development 17 341-348.

Mota-Rojas D, Martinez-Burnes J, Trujillo-Ortega ME, Alonso-Spilsbury ML, Ramirez-Necoechea R \& Lopez A 2002 Effect of oxytocin treatment in sows on umbilical cord morphology, meconium staining, and neonatal mortality of piglets. American Journal of Veterinary Research 63 1571-1574.

Noeker M 2005 Neurocognitive development in children experiencing intrauterine growth retardation and born small for gestational age: pathological, constitutional and therapeutic pathways. Hormone Research 64 (Suppl 3) 83-88.

Pardi G, Marconi AM \& Cetin I 2002 Placental-fetal interrelationship in IUGR fetuses - a review. Placenta (Suppl A) 23 S136-S141.

Randall GC 1972 Observations on parturition in the sow. II. Factors influencing stillbirth and perinatal mortality. Veterinary Record $90183-186$.

Rehfeldt C, Fiedler I, Weikard R, Kanitz E \& Ender K 1993 Is it possible to increase skeletal muscle fibre in utero? Bioscience Reports 13 213-220.

Rehfeldt C, Kuhn G, Nürnberg G, Kanitz E, Schneider F, Beyer M, Nürnberg K \& Ender K 2001 Effects of exogenous somatotropin during early gestation on maternal performance, fetal growth and compositional traits in pigs. Journal of Animal Science 79 1789-1799.

Reyes L \& Manalich R 2005 Long-term consequences of low birth weight. Kidney International Supplement 68 S107-S111.

Sherwin CM, Christiansen SB, Duncan IJ, Erhard HW, Lay DC, Mench JA, O'Connor CE \& Petherick JC 2003 Guidelines for the ethical use of animals in applied ethology studies. Applied Animal Behaviour Science 81 291-305.

Smith VG, Leman AD, Seaman WJ \& Van Ravenswaay F 1991 Pig weaning weight and changes in hematology and blood chemistry of sows injected with recombinant porcine somatotropin during lactation. Journal of Animal Science 69 3501-3510.

Stein AD, Ravelli AC \& Lumey LH 1995 Famine, third trimester pregnancy weight gain, and intrauterine growth: the Dutch famine birth cohort study. Human Biology 67 135-150.

Yanney M \& Marlow N 2004 Paediatric consequences of fetal growth restriction. Seminars in Fetal and Neonatal Medicine 9 411-418.

Received in final form 14 March 2006

Accepted 16 March 2006

Made available online as an Accepted Preprint

31 March 2006 